

\title{
More Health Care Utilisation With More Insurance Coverage? Evidence from a Latent Class Model with German Data
}

Hendrik Schmitz

\section{- To cite this version:}

Hendrik Schmitz. More Health Care Utilisation With More Insurance Coverage? Evidence from a Latent Class Model with German Data. Applied Economics, 2011, pp.1. 10.1080/00036846.2011.591733 . hal-00719479

\section{HAL Id: hal-00719479 \\ https://hal.science/hal-00719479}

Submitted on 20 Jul 2012

HAL is a multi-disciplinary open access archive for the deposit and dissemination of scientific research documents, whether they are published or not. The documents may come from teaching and research institutions in France or abroad, or from public or private research centers.
L'archive ouverte pluridisciplinaire HAL, est destinée au dépôt et à la diffusion de documents scientifiques de niveau recherche, publiés ou non, émanant des établissements d'enseignement et de recherche français ou étrangers, des laboratoires publics ou privés. 


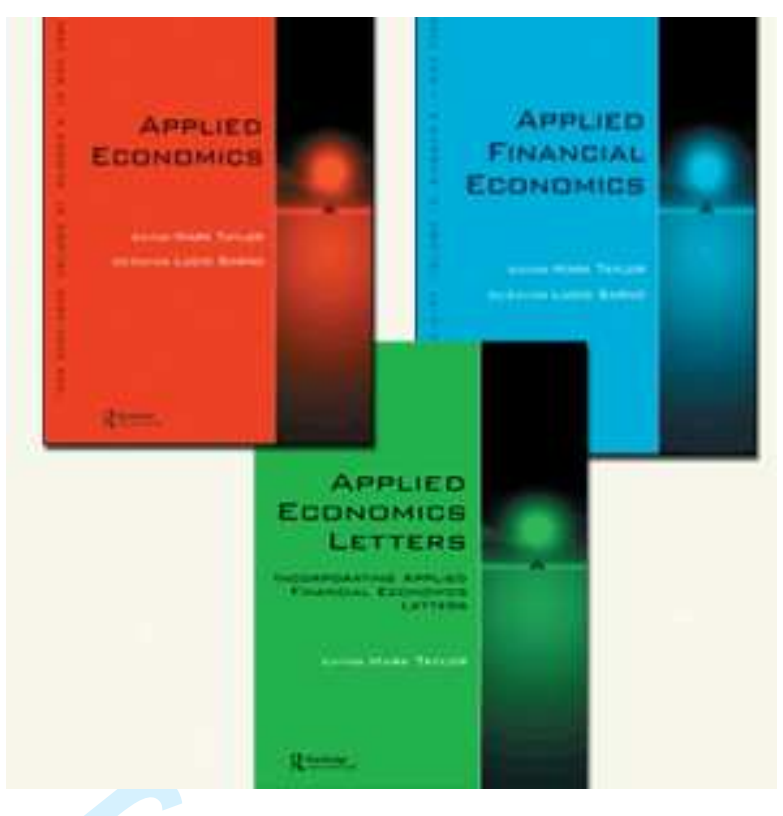

\section{More Health Care Utilisation With More Insurance Coverage? Evidence from a Latent Class Model with German Data}

\begin{tabular}{|c|c|}
\hline Journal: & Applied Economics \\
\hline Manuscript ID: & APE-2009-0467.R1 \\
\hline Journal Selection: & Applied Economics \\
\hline $\begin{array}{l}\text { Date Submitted by the } \\
\text { Author: }\end{array}$ & 19-Nov-2010 \\
\hline Complete List of Authors: & $\begin{array}{l}\text { Schmitz, Hendrik; Ruhr Graduate School in Economics, University } \\
\text { Duisburg-Essen; RWI }\end{array}$ \\
\hline JEL Code: & $\begin{array}{l}\text { I11 - Analysis of Health Care Markets < I1 - Health < I - Health, } \\
\text { Education, and Welfare, I18 - Government Policy|Regulation|Public } \\
\text { Health < I1 - Health < I - Health, Education, and Welfare, G22 - } \\
\text { Insurance|Insurance Companies < G2 - Financial Institutions and } \\
\text { Services < G - Financial Economics }\end{array}$ \\
\hline Keywords: & $\begin{array}{l}\text { health insurance, deductibles, supplementary insurance, count } \\
\text { data, latent class panel model }\end{array}$ \\
\hline
\end{tabular}




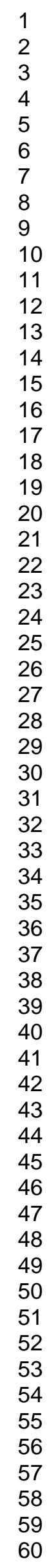

\section{SCHOLARONE ${ }^{m}$ \\ Manuscripts}

7

25

26

27

29

30

32

33

34

35

36

37

39

40

41

42

44

45

46

47

48

49

50

52

53

54

56

57

58

60 


\title{
More Health Care Utilisation With More Insurance Coverage? Evidence from a Latent Class Model with German Data
}

\author{
Hendrik Schmitz* \\ Ruhr Graduate School in Economics, RWI, \\ University of Duisburg-Essen
}

November 19, 2010

\begin{abstract}
We analyse the impact of optional deductibles, private supplementary health insurance and income on the demand for health care utilisation, measured as the number of physician visits with data from the German Socioeconomic Panel. With a set of newly available variables for the years 2002, 2004, and 2006 that measure individual health more accurately and including riskattitudes towards health we find that possible endogeneity of the insurance choice is not a problem. A latent class approach that takes into account the panel structure of the data reveals that especially individuals who have few doctor visits, the low users, respond strongest to insurance status and income. In this group we find that more insurance increases the demand for physician visits and there is a pro-rich inequity in health care utilisation. No such effects are found for the high users.
\end{abstract}

JEL Classification: I11, I18, G22

Keywords: health insurance, deductibles, supplementary insurance, count data, latent class panel model

*All correspondence to Hendrik Schmitz, Rheinisch-Westfälisches Institut für Wirtschaftsforschung (RWI Essen), Hohenzollernstr. 1-3, 45128 Essen, Germany, Fax: +49-201-8149-500, e-mail: schmitz@rwi-essen.de 


\section{Introduction}

Increasing health care expenditures have been an issue for several decades in most industrialised countries. While demographic change and technological progress can be seen as the main driving forces behind the increase, both factors can hardly be tackled in order to contain costs. Thus, it seems more promising to detect and reduce inefficiencies in the health care sector. One inefficiency on the demand side is the problem of moral hazard induced by insurance, defined as "the change in health behavior and health care consumption caused by insurance" (Zweifel and Manning, 2000). If this leads to excess demand for trivial health services, efficiency could be gained by cost-sharing, e.g., deductibles or co-payments for doctor or hospital visits. However, the optimal amount of cost-sharing is a priori unclear. In a world with risk-averse individuals and without moral hazard, full cover insurance (i.e., no deductibles) can be a first-best solution. Yet, when moral hazard is present, the firstbest solution is no longer feasible and the introduction of mandatory deductibles can lead to a second-best solution (see Breyer et al., 2004).

On the other hand, in particular societies in Europe usually aim for a universal coverage of health care services, available to all in need, independent of income (Wagstaff and Van Doorslaer, 2000). Cost-sharing might endanger access to health care services of poorer households and, thus, threaten equity goals in health care utilisation. Moreover, allowing for optional deductibles could lead to a decomposition of the risk pool as it can be assumed that good risks choose to buy less insurance to safe on insurance contributions whereas bad risks are left with higher premiums. Therefore, deductibles might also induce a welfare loss since less insurance coverage lowers the expected utility of risk averse individuals.

Hence, finding out more about the price elasticity of demand for health services is an important empirical task in order to design an optimal health insurance system. This study analyses the price elasticity of demand for health services in Germany. In particular, we examine whether (a) optional deductibles in private health insurance 
or (b) absence of private supplementary insurance cause a lower utilisation of health care services and, thus, are able to increase efficiency in the health care sector, or if they only lead to a decomposition of the risk pool. Second, we evaluate whether utilisation varies with income conditional on individual need.

There are several studies that analyse the impact of the insurance status on the number of doctor visits or hospitalisations with German panel data, e.g., Pohlmeier and Ulrich (1995), Geil et al. (1997), and Riphahn et al. (2003). They compare the behaviour of individuals covered by private health insurance with those covered by public insurance. In the German system, the former can choose between having a deductible or not, whereas there are basically no deductibles for the latter. The results of these studies are mixed. Pohlmeier and Ulrich (1995) find that the probability of visiting a general practitioner (GP) is higher for the publicly insured, that is, implicitly, for those with more insurance coverage. Geil et al. (1997) show that, for females, being covered by public insurance has a positive (but moderate) effect on the number of hospitalisations, while no significant effect was found for males. Riphahn et al. (2003) find that private add-on insurance raises the number of hospitalisations of males, while other variables that indicate the insurance status are not significant. Felder and Werblow (2008) evaluate an experiment of one German sickness fund that allowed a subset of voluntarily insured to choose a contract with a deductible in 2003. They find that the deductible reduces the probability of visiting a specialist but not a GP. Furthermore the deductible reduced health care expenditures for acute care but not for preventive care. However, the authors' control for the notable selection of healthy individuals into the deductible program rests on strong assumptions (basically, the validity of exclusion restrictions).

The contribution of this study is threefold. First, we take unobserved heterogeneity into account in a fairly general way. By exploiting the panel structure of the data, Riphahn et al. (2003) and Geil et al. (1997) already account for unobserved individual effects that influence doctor visits using a random effects model. Here, however, we estimate a finite mixture model that allows for different effects of insurance sta- 
tus and income for different latent classes. Latent class models were introduced to the health economics literature by Deb and Trivedi (1997) and have become very popular since then. ${ }^{1}$ In the present study, we use the latent class hurdle model developed by Bago d'Uva (2006).

Second, we bear in mind that privately and publicly insured individuals differ in many aspects, especially in their offered insurance contracts and their latent health status. Therefore, we run separate regressions for both groups. Third, we use recent innovations in the German Socio-Economic Panel and include better health measures and a directly stated measure of risk aversion in the analysis. Doing this, we are much more likely to reduce a possible omitted variable bias that renders the insurance choice an endogenous explanatory variable than previous German studies. Endogeneity of the insurance status might occur for two reasons: unobserved health status and unobserved risk aversion. When making a decision about the insurance plan, the individual takes into account her expected demand for health services in the future. A person who knows that she will need many visits to the doctor in the future due to health problems might not buy insurance with deductibles. Thus, the health status both affects the demand for doctor visits and the insurance type so that an incompletely observed health status might lead to biased results. Similar reasoning applies to preferences like risk aversion. Risk-averse individuals might prefer full cover insurance and at the same time demand more doctor visits given a certain health status. However, it is also possible that the reverse is true: higher demand for health insurance but less demand for health services since risk averse individuals might be in better health due to higher preventive efforts, see de Meza and Webb (2001), Finkelstein and McGarry (2006), or Cutler et al. (2008).

We use the waves 2002, 2004, and 2006 of the German Socio-economic panel (SOEP)

\footnotetext{
${ }^{1}$ Recently they were used in different specifications by, e.g., Deb and Holmes (2000), Deb (2001), Gerdtham and Trivedi (2001), Deb and Trivedi (2002), Jimenez-Martin et al. (2002), Atella et al. (2004), Bago d'Uva (2005), Bago d'Uva (2006), Bago d'Uva and Jones (2009), Zheng and Zimmer (2010). Latent class models also became increasingly popular in other fields of economics, see, e.g. Shen (2009), or Greene and Hensher (2003) for applications using transport mode choice data.
} 
that include newly available health measures from a version of the SF12v2-questionnaire and a directly stated degree of risk aversion to overcome this endogeneity problem. It turns out that deductibles and private supplementary insurance affect the doctor visiting behaviour at least to a certain degree. Specifically, individuals who generally have a lower demand for doctor visits do react on the imposed incentives given by the insurance status. They demand less doctor visits with a deductible and more with private supplementary insurance. No significant effects can be found in the group of high users. As regards income elasticity we find positive effects in the low user group and mostly small and insignificant effects for high users.

The paper is structured as follows. Section 2 gives a brief introduction into the German health insurance system. Section 3 describes the data and the empirical strategy, while Section 4 presents the estimation results. Section 5 discusses endogeneity concerns and Section 6 concludes.

\section{Institutional Background}

The German health insurance system consists of two parts. Roughly 88 per cent of the population are insured by public health insurance (also called the statutory health insurance, SHI). It is statutory for all individuals with earnings below a certain income threshold (3,975 Euro per month in 2007) and financed by payroll taxes. Until the most recent reform which took effect in April 2007, there were basically no (optional) deductibles in the public scheme. ${ }^{2}$ The publicly insured can additionally purchase private supplementary insurance, also called add-on insurance, that either increases quality (e.g. double rooms in hospitals) or covers co-payments on dentures, corrective devices (like glasses) or other remedies.

\footnotetext{
${ }^{2}$ However, in 2004, a co-payment of 10 Euro for the first visit in a quarter was introduced. No effects of this reform on the demand for doctor visits are found by Augurzky et al. (2006) and Schreyögg and Grabka (2010). Since they use the same data set as we do, we do not take this reform into account. Also, since our latest year of analysis is 2006, the reform of 2007 is of no importance for this study.
} 


\section{Empirical Model}

\subsection{Data and Variable Description}

The database for the empirical analysis is the German Socioeconomic Panel (SOEP) which started in 1984. There were several refreshments resulting in a sample size of more than 20,000 adult individuals living in more than 12,000 households in 2006 (see, e.g., Wagner et al., 2007). ${ }^{3}$ The SOEP asks about the number of doctor visits within the last three months prior to the interview. This number depends to a large extent on the individual health status. Two newly available and more objective measures of health are used here to accompany the usually employed self-assessed health status (SAH) with its well-known problems (see, e.g., Crossley and Kennedy, 2002, or Jürges, 2008): the Physical Component Summary Scale (PCS), a measure of physical health, and the Mental Component Summary Scale (MCS) a measure

\footnotetext{
${ }^{3}$ The data used in this paper were extracted using the Add-On package PanelWhiz v2.0 (Nov 2007) for Stata. PanelWhiz was written by Dr. John P. Haisken-DeNew (john@panelwhiz.eu). The PanelWhiz generated DO file to retrieve the SOEP data used here and any Panelwhiz Plugins are available upon request. Any data or computational errors in this paper are my own. HaiskenDeNew and Hahn (2006) describe PanelWhiz in detail.
} 
of mental health (see Andersen et al. (2007) for a description). These measures are based on a variant of the SF12v2-questionnaire in the SOEP that includes several questions about health quality and satisfaction of the individuals. ${ }^{4}$ Both variables are calculated using explorative factor analysis and lie between 0 and 100, with a higher value indicating a better health status. Although both measures are also based on self-reported information, they give a much more detailed picture of the true health status. As an objective measure of individual health we use the body mass index (BMI) and whether there was a hospital stay in the previous year. The three variables PCS, MCS, and BMI are only available in the waves 2002, 2004, and 2006, hence, these three waves of the SOEP are used for the analysis.

One further variable that is newly available in the SOEP is a self-assessed attitude towards risk concerning health matters on an 11-point scale from 0 (very risk-averse) to 10 (not at all risk-averse). ${ }^{5}$ The risk attitude is likely to have an important impact on the demand for health care. It was only asked in 2004. However, it seems reasonable to assume that this personality trait is constant over the duration of five years. Although the attitude towards risks is self-assessed, Dohmen et al. (2010) show in an experimental setting with a pre-test group of the SOEP that it is a fairly reliable measure. Using these new variables (together with a set of other socio economic variables which are not the focus of this study), we can control for a lot of important heterogeneity that has an effect on the number of doctor visits and the insurance status at the same time and which remained unobserved in previous studies.

In our sample, only the privately insured are allowed to buy contracts with deductibles. The information in the data on deductibles of the privately insured is restricted to a binary indicator variable. The publicly insured state what kind of private add-on insurance they hold. We collapse these into a binary variable indi-

\footnotetext{
${ }^{4}$ Questions concern, among others, bodily pain, stress, ability to carry out everyday tasks, phases of melancholy, etc.

${ }^{5}$ The question in the SOEP is: "How would you rate your willingness to take risks with your health?"
} 


\section{- Table 1 about here -}

The number of doctor visits in the previous three months of several groups with different insurance statuses in the pooled sample is given in Table 1 . The overall mean is 2.44 , with 32 per cent of all individuals not having any doctor visit. Conditional on having at least one visit, the average number of doctor visits in the whole sample is 3.57. Publicly insured exhibit a higher number than privately insured (2.47 vs. 2.20). However, both groups are hardly comparable because the group of privately insured consists of individuals with higher income and better education and especially better health (see Table A1 in the Appendix for means of the covariates for different subgroups). Therefore, and because the insurance contracts of both groups differ substantially, we carry out separate estimations for both groups in the regression analysis below.

The comparison of the privately insured with and without deductible shows that those with a deductible have much less doctor visits (1.96 vs. 2.50), a lower probability of visiting a doctor (58 per cent vs. 67 per cent), and even fewer doctor visits 
conditional on having at least one visit (3.36 vs. 3.74). Likewise, individuals with add-on insurance exhibit slightly higher numbers of doctor visits.

\subsection{Latent Class Hurdle Model}

It is often argued that the observed number of doctor visits is a result of two different decision-making processes. First, the patient decides whether or not to see a doctor in case of an illness. Once a doctor is seen, however, the doctor - maybe together with the patient - determines the length of the treatment. Hence, a hurdle model seems to be the most appropriate formulation in order to explain the number of doctor visits (see Mullahy, 1986; Pohlmeier and Ulrich, 1995). Given that the dependent variable (number of doctor visits in the previous three months) is an integer, we use a negative binomial model in order to specify the two underlying functions in the hurdle model. Thereby, after normalising the over-dispersion parameter of the negative binomial distribution to 1 , the first stage (binary decision) reduces to a logit. The second stage (number of recalls given at least one visit) is a truncated-at-zero negative binomial model.

While the included covariates capture a lot of observable heterogeneity between individuals and across time, there might still be great a deal of unobservable heterogeneity left. In order to account for this unobserved heterogeneity, we use the latent class hurdle model derived by Bago d'Uva (2006) for panel count data in which the individual effect follows a discrete distribution that takes on a small number of components. The latent class hurdle model combines the basic hurdle model (that groups individuals into "users" and "non-users") with a finite mixture model (where the latent classes can be given interpretations such as "high users" and "low users", see Deb and Trivedi, 2002).

As in Bago d'Uva (2006), the individual probability of belonging to one of $C$ latent 
classes is specified as a multinomial logit.

$$
\pi_{i j}=\frac{\exp \left(z_{i}^{\prime} \gamma_{j}\right)}{\sum_{g=1}^{C} \exp \left(z_{i}^{\prime} \gamma_{g}\right)}, j=1, \ldots, C
$$

This ensures that $0<\pi_{i j}<1$ and $\sum_{j=1}^{C} \pi_{i j}=1$. In order to guarantee that each individual belongs to the same latent class over all time periods, we choose the $z_{i}$ as time-invariant characteristics. We follow Bago d'Uva (2005) in using the individual averages of the included covariates $\left(x_{i t}\right)$, defining $z_{i}=\bar{x}_{i}$. Note that this specification allows for correlation between the observable characteristics and the unobserved individual heterogeneity (that is, here, the latent class). The likelihood function is finally given by

$$
L=\prod_{i=1}^{N} \sum_{j=1}^{C} \pi_{i j}\left(z_{i}, \gamma_{j}\right) \prod_{t=1}^{T_{i}} g_{j}\left(y_{i t} \mid x_{i t}, \beta_{1 j}, \beta_{2 j}, \alpha_{j}\right)
$$

where $g($.$) is the density function of the negative binomial hurdle model, \beta_{1 j}$ and $\beta_{2 j}$ are the vectors of coefficients of the two hurdle parts, and $\alpha_{j}$ is the over-dispersion parameter of the negative binomial distribution. The most flexible formulation allows for different slope parameters in every latent class $\left(\beta_{1 j} \neq \beta_{1 k}\right.$ and $\beta_{2 j} \neq \beta_{2 k}$ for $j \neq k)$ and different parameters in the two hurdle parts $\left(\beta_{1 j} \neq \beta_{2 j}\right)$. This, however, requires the estimation of a huge number of parameters and is, thus, very data-demanding. Since we only have three waves and, furthermore, carry out different regressions for publicly and privately insured, we restrict the model to the same slope parameters across latent classes and allow only for heterogeneity in the most interesting parts. These are: the intercept, the over-dispersion parameters and the two insurance variables (deductible or add-on) plus the equivalised net household income. The likelihood function is maximized with respect to the vectors $\theta_{1}, \ldots, \theta_{C}, \gamma_{1}, \ldots, \gamma_{C-1}$ using the Broyden-Fletcher-Goldfarb-Shanno quasi-Newton algorithm. ${ }^{6}$ Note that in this specification, the two parts of the hurdle model are

\footnotetext{
${ }^{6}$ We used the $m l$ command in Stata and drawed on the code provided in Jones et al. (2007). Various starting values were used to rule out local maxima of the likelihood function.
} 
linked via the latent classes. The restrictive assumption of independence of both stages in the standard hurdle model is, therefore, relaxed.

\section{Estimation Results}

We carry out separate regressions for both groups of insured (SHI and private insurance) where the insurance variable in the case of SHI is the binary indicator of holding add-on insurance and in the case of private insurance it is the dummy for a deductible. The model selection, that is, the choice of the number of components is done by the Akaike criterion (AIC). Table 2 shows different values of AIC for different choices of components. In both cases the latent class panel model outperforms the standard hurdle model with a logit as the first part and a truncated negative binomial model as a second part (which is equivalent to the latent class model with only one component). Hence, the fit is improved substantially by capturing unobserved individual effects. According to the AIC, the model with three components is preferred for the privately insured over the one with two components. In the SHI sample, the model with three components failed to converge. However, it is widely accepted in the literature that two components already capture a substantial part of individual unobserved heterogeneity. A model with four components did not converge in either case.

\section{- Table 2 about here -}

Based on the estimated parameters and the observed covariates we calculate both the individual predicted number of doctor visits (for all latent classes) and the individual likelihood of belonging to one of the three (or two in the case of SHI) latent classes. Table 3 reports average probabilities for the different classes and average predicted values. Based on the predicted numbers of visits we call the classes the "low users", "medium users" and "high users". Each group has a reasonably high share. The high 
users have a share of about one third, whereas low users or low and medium users account for the remaining two thirds.

\section{- Table 3 about here -}

Due to the nonlinearity of the model, the interpretation of the estimated parameters is not straightforward. Therefore, we focus on the calculated marginal effects of the most interesting variables (Table 4). They are calculated in the following way: first, we compute the marginal effect of every individual in each latent class. Then, we average over all individual marginal effects within all latent classes. The full regression results can be found in Tables A2 and A3 in the Appendix.

The effects of the insurance variables vary with the latent classes. Both low users and medium users in the private insurance have a lower likelihood of at least one doctor visit (first stage) in case of a contract with deductible. For the low users (medium users), a deductible is associated with a reduced probability of at least one doctor visit by 7.1 percentage points (6.6 percentage points). But only for the low users the effect is significant at the 5 per cent-level. Likewise, the effect is negative but insignificant for both low and medium users in the second stage. The same results hold for the low users in the SHI. Here, more insurance implies more doctor visits, significant in both the first and the second stage. As an example, in the group of low users, add-on insurance is associated with a 5.8 percentage point higher likelihood of a doctor visit and with, on average, 0.549 more conditional doctor visits (i.e., conditional on one visit) compared to not holding add-on insurance. On the other hand, the insurance status does not significantly affect the behaviour of high users in both samples where the coefficients even have unexpected signs. All together, especially low users appear to react on the incentives given by the insurance status. These results are in line with those found in Deb and Trivedi (1997) and Bago d'Uva (2006). However, given an average probability of seeing a doctor within three months of 68 per cent, a reduction by 7.1 percentage points (deductible/low users) 
or an increase by 5.8 percentage points appears to be rather small even though being significant.

Concerning equivalised household income, the results differ again by latent classes. Only small (and mostly insignificant) effects can be found in both groups of high users. In the group of low and medium users, however, higher income is associated with more doctor visits. This especially holds for a higher likelihood of at least one visit (i.e., the first stage). For example, the marginal effects in the group of low users in the SHI imply that increasing the equivalised net household income by 1 per cent (this would amount to about 15 Euro for the average household in the sample) is associated with an approximately 0.034 percentage points higher likelihood of a first visit and with 0.00119 more conditional visits, since the income is measured in logs. The magnitudes are higher for the low and medium users in the private insurance. Thus, after controlling for the health status and other important factors like age and sex this result points into the direction of a pro-rich inequity, although being fairly small in economic terms. This is again in line with the results of previous international studies using finite mixture models. However, most other studies find a positive income effect for all latent classes but a stronger one for the low users (e.g., Deb and Trivedi, 2002, Bago d'Uva, 2005, Bago d'Uva, 2006). Here, this only holds for the group of SHI insured. Studies that do not use latent class models also often find income-related inequity favouring richer individuals, mostly as regards specialist visits (e.g. Doorslaer et al., 2004, Allin et al., 2010) but also as regards GP visits (Allin et al., 2010). However, the results are not perfectly comparable as we cannot distinguish between GPs and specialists and we run different estimations for privately and publicly insured. It may well be that, taking both groups together, there would be a positive effect in all latent classes.

Some authors explain their results of income-related inequities with a better access to medical services (Doorslaer et al., 2004). Since we estimate the effects separately for the two insurance systems it is unlikely that this is the reason for our result here because within the two systems there is no incentive for doctors to give preferential 


\section{- Table 4 about here -}

We briefly summarise the results of the newly available variables. The estimated parameters are reported in Table A2. Both higher PCS and higher MCS (indicating a healthier individual) are associated with significantly less doctor visits, where the effect of physical health is stronger than the one of mental health. A very high bodymass index (>30) increases the number of visits for the publicly insured. The risk attitude towards health also has the expected sign (more risk-averse individuals have more doctor visits, conditional on the health status) and is significant in the first stage in the group of privately insured. Altogether, the new variables significantly add to the explanation of the demand for physician visits.

\section{Endogeneity concerns}

When analysing the impact of health insurance on the demand for health care services, there is possibly an endogeneity problem. As discussed in the Introduction, this problem might stem from omitted variable bias due to unobserved health status and unobserved risk-preferences. However, including the new set of health and risk variables possibly reduces the endogeneity problem.

Given the principal-agent interpretation of the hurdle model, one can argue that possible endogeneity of the insurance choice should mainly play a role in the first 
stage, namely when the patient has full control. This is corroborated by the regression results that mainly showed significant effects of the insurance variables in the first and not the second stage (with one exception). Thus, as a specification test, to determine if endogeneity is a problem, we focus on that stage and model the decision to see a doctor together with the decision about a certain insurance contract. Consider the following bivariate model

$$
\begin{aligned}
& y_{1}=1\left[x_{1} \beta_{1}+h \delta_{1}+\alpha_{1} y_{2}+\mu_{1}>0\right] \\
& y_{2}=1\left[x_{2} \beta_{2}+h \delta_{2}+\mu_{2}>0\right]
\end{aligned}
$$

where $y_{1}$ is the binary decision to see a doctor and $y_{2}$ the binary decision about the insurance contract (i.e., deductible yes/no, or add-on insurance yes/no), $h$ is the observed health status, and $x_{1}$ and $x_{2}$ are vectors of socio-economic variables like age, education, and income. Finally, $\mu_{1}$ and $\mu_{2}$ capture unobserved effects like unobserved health and preferences towards visiting a doctor. We assume that the number of doctor visits in one period depends on the insurance status whereas the insurance status does not depend on the number of doctor visits in the same period (given a certain health status). The correlation between $\mu_{1}$ and $\mu_{2}, \rho=\operatorname{corr}\left(\mu_{1}, \mu_{2}\right)$, does not equal 0 if the unobserved factors that affect the number of doctor visits and the insurance choice are correlated. Assuming a bivariate normal distribution of the error terms, the parameters of this model (and the correlation $\rho$ ) can be estimated by a bivariate probit.

Again, we fit two separate regressions for deductibles and add-ons. In the first regression, $\rho$ can be expected to be negative if the insured who expect to have fewer doctor visits in the future (for unobserved reasons) tend to buy insurance with a deductible. In contrast, add-on insurance leads to more insurance coverage, hence, a positive $\rho$ can be expected in the second regression.

We add variables to $x_{2}$ that are assumed not to affect the decision to visit a doctor 


\section{- Table 5 about here -}

In the deductible equation, the sign is different from what is expected. However, the value is very close to zero in both cases. It can be argued that capturing information from the new health variables and the degree of risk-aversion together with all the other socio-economic variables reduces the endogeneity problem by a substantial amount. However, one can think of even more reasons originating in the insurance system that render endogeneity being much less of a problem than possibly expected. As discussed in Section 2, opting out of private insurance and deciding on deductibles are practically lifetime decisions. While the (partly unobserved) health status should have a high impact on the decision about health insurance in a given year, it only affects the number of doctor visits in the following years but not the decision about the insurance type. Moreover, Grabka (2006) gives another reason for the privately insured to switch to a contract with a deductible that is independent of changes in the health status of the insured. Unlike in the case of public insurance, cost containment and the stability of contribution rates have not been considered in the past decades in the private insurance system. This has led to a much higher proportional increase in costs than in the SHI and, thus, to steadily increasing contribution rates for the privately insured. One way for an insured to stop the

\footnotetext{
${ }^{7}$ Risk-aversion concerning financial matters is asked for in the same way as the risk-aversion concerning health. The question about the attitudes towards co-payments was asked only in 2002. As in the case of risk-aversion, we assume that this is a time-invariant preference.
} 
rise in the contribution rate in a given year is to transform a contract without a deductible into one with a deductible to keep the basic insurance premium stable. In this case, the decision about buying insurance with a deductible is not affected by a change in the health status but by other reasons. Together with the performed statistical tests this supports the idea that the results of the previous section are not biased by endogeneity problems.

\section{Conclusion}

In this paper, we analyse the income elasticity of German individuals with respect to the utilisation of health care services and the effect of health insurance coverage measured by the existence of deductibles for privately insured and add-on insurance for publicly insured. With a flexible hurdle model that accounts for individual unobserved heterogeneity, we observe that newly available health measures in the SOEP from the SF12v2-questionnaire (physical and mental health scores), the BMI, and a measure of risk-aversion can partly explain the demand for physician visits. Altogether, tests suggest that possible endogeneity of the insurance status is not an issue in the data set.

We find significant effects of health insurance on the demand for physician visits and that richer individuals tend to have more doctor visits conditional on their individual needs. Both effects, however, are only found in the group of low users, that is, those who only have a low probability to see a doctor from the outset. In the group of high users, neither do deductibles seem to have an effect on cost-consciousness, nor does private supplementary insurance increase the demand for physician visits of publicly insured. Apparently, these individuals need physician visits anyway, irrespective of their insurance status. Therefore, in this group, optional deductibles rather seem to spur on the decomposition of the risk-pool instead of increasing efficiency.

The findings for the group of low users, however, show that there are indeed incentive 
effects in the German health insurance. This is in line with the results of the famous RAND health insurance experiment (RHIE) that showed strong effects of co-payments on the demand for health care services in the US in a large experimental setting (Manning et al., 1987). Bago d'Uva (2006) uses the same RHIE data to estimate a similar finite mixture model as this paper. Although the two data sets and institutions are different, the results in both studies (stronger effects of insurance for the low users and in the first stage) are similar. This also holds for the comparison with the recent literature on other countries using finite mixture models.

Some qualifications have to be made. First of all, this study does not give a clear answer to the trade-off between equity and efficiency in the German health care sector. It cannot be argued that deductibles are ineffective and should therefore be abolished in order to increase equity without a loss of efficiency. On the contrary, the findings show that they may well have an effect. However, strong reactions cannot be expected from the group that needs health care utilisation the most (the high users) if the amount of mandatory or optional deductibles is increased by the policymaker. Moreover, the finding of an already existing pro-rich inequity, although being small, presents a possible problem of increased cost-sharing.

The second qualification concerns the separation of moral hazard and adverse selection. Both are problems that arise from the information asymmetry of insurer and insured and lead to a higher utilisation of health care of individuals with more insurance. Thus, observing a higher number of doctor visits of those with more insurance does not necessarily imply moral hazard. However, insurance contracts with deductibles as well as private supplementary insurance are offered by private insurance companies who are allowed to collect detailed information on the health status at the time the insurance contract is signed. Therefore, the degree of ex-ante information asymmetry which possibly leads to adverse selection is reduced by the comprehensive information of the insurance companies. Nevertheless, the measured incentive effects should be seen as an upper bound. Finally, this study focusses on the demand side of health care utilisation. Thus, supply-side factors (like doctor's 
preferences) that possibly affect the demand for health care services are neglected here.

\section{Acknowledgements}

I am grateful to Daniel Baumgarten, Stefan Felder, Annika Herr, Hendrik Jürges, Annika Meng, Alfredo Paloyo, Wolfram Richter, Reinhold Schnabel, and Nicolas Ziebarth for valuable comments on earlier versions of the paper. Moreover, I want to thank an anonymous referee for improving the paper. This paper benefited from discussion at the EEA annual meeting 2008 in Milan, the 2nd RGS doctoral conference in Essen, and the annual meeting of Verein für Socialpolitik 2008 in Graz. Financial support by the Leibniz association is gratefully acknowledged. All errors are my own.

\section{References}

Allin, S., Masseria, C., and Mossialos, E. (2010). Equity in health care use among older people in the UK: An analysis of panel data. Applied Economics, (forthcoming, published online 21 April 2010).

Andersen, H. H., Mühlbacher, A., Nübling, M., Schupp, J., and Wagner, G. G. (2007). Computation of standard values for physical and mental health scale scores using the SOEP version of SF12v2. Schmollers Jahrbuch: Journal of Applied Social Science Studies / Zeitschrift für Wirtschafts- und Sozialwissenschaften, 127(1):171-182.

Atella, V., Brindisi, F., Deb, P., and Rosati, F. C. (2004). Determinants of access to physician services in Italy: A latent class seemingly unrelated probit approach. Health Economics, 13(7):657-668.

Augurzky, B., Bauer, T. K., and Schaffner, S. (2006). Copayments in the German health system: Does it work? IZA Discussion Paper, (2290).

Bago d'Uva, T. (2005). Latent class models for use of primary care: Evidence from a British panel. Health Economics, 14(9):873-892.

Bago d'Uva, T. (2006). Latent class models for health care utilisation. Health Economics, 15:329-343. 
Bago d'Uva, T. and Jones, A. M. (2009). Health care utilisation in Europe: New evidence from the ECHP. Journal of Health Economics, 28(2):265-279.

Breyer, F., Zweifel, P., and Kifmann, M. (2004). Gesundheitsökonomik. Springer, Berlin Heidelberg New York, fifth edition.

Crossley, T. F. and Kennedy, S. (2002). The reliability of self-assessed health status. Journal of Health Economics, 21(4):643-658.

Cutler, D. M., Finkelstein, A., and McGarry, K. (2008). Preference heterogeneity and insurance markets: Explaining a puzzle of insurance. American Economic Review, 98(2):157-62.

de Meza, D. and Webb, D. C. (2001). Advantageous selection in insurance markets. RAND Journal of Economics, 32(2):249-62.

Deb, P. (2001). A discrete random effects probit model with application to the demand for preventive care. Health Economics, 10(5):371-383.

Deb, P. and Holmes, A. M. (2000). Estimates of use and costs of behavioural health care: A comparison of standard and finite mixture models. Health Economics, $9(6): 475-489$.

Deb, P. and Trivedi, P. K. (1997). Demand for medical care by the elderly: A finite mixture approach. Journal of Applied Econometrics, 12(3):313-36.

Deb, P. and Trivedi, P. K. (2002). The structure of demand for health care: Latent class versus two-part models. Journal of Health Economics, 21(4):601-625.

Dohmen, T., Falk, A., Huffman, D., Sunde, U., Schupp, J., and Wagner, G. G. (2010). Individual risk attitudes: Measurement, determinants and behavioral consequences. Journal of the European Economic Association, (forthcoming).

Doorslaer, E. V., Koolman, X., and Jones, A. M. (2004). Explaining income-related inequalities in doctor utilisation in Europe. Health Economics, 13(7):629-647.

Felder, S. and Werblow, A. (2008). A physician fee that applies to acute but not to preventive care: Evidence from a German deductible program. Schmollers Jahrbuch : Journal of Applied Social Science Studies / Zeitschrift für Wirtschaftsund Sozialwissenschaften, 128(2):191-212.

Finkelstein, A. and McGarry, K. (2006). Multiple dimensions of private information: Evidence from the long-term care insurance market. American Economic Review, 96(4):938-958.

Geil, P., Million, A., Rotte, R., and Zimmermann, K. F. (1997). Economic incentives and hospitalization in Germany. Journal of Applied Econometrics, 12(3):295-311.

Gerdtham, U.-G. and Trivedi, P. K. (2001). Equity in Swedish health care reconsidered: New results based on the finite mixture model. Health Economics, 10(6):565-572. 
Grabka, M. M. (2006). Prämien in der PKV: Deutlich stärkerer Anstieg als in der gesetzlichen Krankenversicherung. DIW Wochenbericht, 73(46):653-659.

Greene, W. H. and Hensher, D. A. (2003). A latent class model for discrete choice analysis: Contrasts with mixed logit. Transportation Research Part B: Methodological, 37(8):681-698.

Haisken-DeNew, J. P. and Hahn, M. (2006). Panelwhiz: A flexible modularized stata interface for accessing large-scale panel data sets.

Jimenez-Martin, S., Labeaga, J. M., and Martinez-Granado, M. (2002). Latent class versus two-part models in the demand for physician services across the European Union. Health Economics, 11(4):301-321.

Jones, A., Rice, N., Bago d'Uva, T., and Balia, S. (2007). Applied Health Economics.

Jürges, H. (2008). Self-assessed health, reference levels and mortality. Applied Economics, 40(5):569-582.

Knapp, L. G. and Seaks, T. G. (1998). A Hausman test for a dummy variable in probit. Applied Economics Letters, 5(5):321-23.

Manning, W., Newhouse, J., Duan, N., Keeler, E., Leibowitz, A., and Marquis, M. (1987). Health insurance and the demand for medical care: Evidence from a randomized experiment. American Economic Review, 77:251-277.

Mullahy, J. (1986). Specification and testing of some modified count data models. Journal of Econometrics, 33(3):341-365.

Pohlmeier, W. and Ulrich, V. (1995). An econometric model of the two-part decisionmaking process in the demand for medical care. Journal of Human Resources, 30:339-361.

Riphahn, R. T., Wambach, A., and Million, A. (2003). Incentive effects in the demand for health care: A bivariate panel count data estimation. Journal of Applied Econometrics, 18(4):387-405.

Schreyögg, J. and Grabka, M. M. (2010). Copayments for ambulatory care in Germany: A natural experiment using a difference-in-difference approach. The European Journal of Health Economics, 11(3):331-341.

Shen, J. (2009). Latent class model or mixed logit model? A comparison by transport mode choice data. Applied Economics, 41(22):2915-2924.

Wagner, G. G., Frick, J. R., and Schupp, J. (2007). The German Socio-Economic Panel Study (SOEP): Scope, evolution, and enhancements. Schmollers Jahrbuch : Journal of Applied Social Science Studies / Zeitschrift für Wirtschafts- und Sozialwissenschaften, 127(1):139-169.

Wagstaff, A. and Van Doorslaer, E. (2000). Equity in health care finance and delivery. In Culyer, A. J. and Newhouse, J. P., editors, Handbook of Health Economics, volume 1, pages 1803-1862. 
Zheng, X. and Zimmer, D. M. (2010). Modelling bivariate count distributions with finite mixture models: Application to health care demand of married couples. Applied Economics, (forthcoming, published online 01 October 2009).

Zweifel, P. and Manning, W. G. (2000). Moral hazard and consumer incentives in health care. In Culyer, A. J. and Newhouse, J. P., editors, Handbook of Health Economics, volume 1, pages 409-459. 


\section{Tables}

Table 1: Doctor Visits of Subgroups

\begin{tabular}{l|cc|cc|cc|c}
\hline & $\begin{array}{c}\text { Average } \\
\text { \# of } \\
\text { visits }\end{array}$ & sd & $\begin{array}{c}\text { Probability } \\
\text { of one } \\
\text { visit }\end{array}$ & sd & $\begin{array}{c}\text { Average } \\
\text { \# of visits } \\
\text { if }>0\end{array}$ & sd & $\begin{array}{c}\text { Number } \\
\text { of } \\
\text { obs. }\end{array}$ \\
\hline Whole Sample & 2.44 & 3.97 & 0.68 & 0.47 & 3.57 & 4.36 & 51894 \\
Public Insurance & 2.47 & 3.95 & 0.69 & 0.46 & 3.58 & 4.31 & 46319 \\
- with add-on & 2.56 & 4.16 & 0.71 & 0.45 & 3.58 & 4.53 & 3644 \\
- without add-on & 2.47 & 3.93 & 0.69 & 0.46 & 3.58 & 4.29 & 42675 \\
Private Insurance & 2.20 & 4.16 & 0.62 & 0.49 & 3.54 & 4.80 & 5551 \\
- with deductible & 1.96 & 3.86 & 0.58 & 0.49 & 3.36 & 4.57 & 3081 \\
- without deductible & 2.50 & 4.48 & 0.67 & 0.47 & 3.74 & 5.04 & 2470 \\
\hline
\end{tabular}

Source: SOEP, pooled years 2002, 2004, 2006; no civil servants.

Table 2: Model selection

\begin{tabular}{c|cc} 
Components & $\begin{array}{c}\text { Private } \\
\text { AIC }\end{array}$ & $\begin{array}{c}\text { SHI } \\
\text { AIC }\end{array}$ \\
\hline 1 & 19,877 & 175,897 \\
2 & 19,636 & 172,786 \\
3 & 19,532 & - \\
\hline \multicolumn{2}{l}{ Source: Own calculations }
\end{tabular}

Source: Own calculations

Table 3: Shares of individuals within each latent class and predicted numbers of physician visits

\begin{tabular}{|c|c|c|c|c|}
\hline & \multicolumn{2}{|c|}{ Sample deductibles } & \multicolumn{2}{|c|}{ Sample add-on } \\
\hline & $\begin{array}{c}\text { Share of } \\
\text { individuals }\end{array}$ & $\begin{array}{c}\text { Predicted } \\
\text { mean }\end{array}$ & $\begin{array}{l}\text { Share of } \\
\text { individuals }\end{array}$ & $\begin{array}{c}\text { Predicted } \\
\text { mean }\end{array}$ \\
\hline Low users & 0.43 & 0.84 & 0.67 & 1.57 \\
\hline Medium users & 0.25 & 2.19 & - & - \\
\hline High users & 0.32 & 3.58 & 0.33 & 4.15 \\
\hline
\end{tabular}

Predicted values based on regression results in Table A2. Predicted shares of

latent classes are calculated based on the results in Table A3 
Table 4: Marginal effects of insurance and income variables for all latent classes

\begin{tabular}{l|c|cc|cc|cc} 
Sample & $\begin{array}{c}\text { Latent } \\
\text { class }\end{array}$ & $\begin{array}{c}\text { Deductible } \\
\text { 1st stage }\end{array}$ & $\begin{array}{c}\text { Deductible } \\
\text { 2nd stage }\end{array}$ & $\begin{array}{c}\text { Add-on } \\
\text { 1st stage }\end{array}$ & $\begin{array}{c}\text { Add-on } \\
\text { 2nd stage }\end{array}$ & $\begin{array}{c}\text { Income } \\
\text { 1st stage }\end{array}$ & $\begin{array}{c}\text { Income } \\
\text { 2nd stage }\end{array}$ \\
\hline \hline Priv. & Low users & $-0.071^{*}$ & -0.358 & & & $0.082^{*}$ & 0.157 \\
Ins. & & $(0.031)$ & $(0.216)$ & & & $(0.024)$ & $(0.132)$ \\
& \multirow{2}{*}{ Medium users } & -0.066 & -1.175 & & & $0.125^{*}$ & 0.589 \\
& & $(0.038)$ & $(0.980)$ & & & $(0.040)$ & $(0.319)$ \\
& \multirow{3}{*}{ High users } & 0.075 & 1.623 & & & -0.016 & -0.140 \\
& & $(0.039)$ & $(1.058)$ & & & $(0.034)$ & $(0.277)$ \\
\hline \multirow{2}{*}{ SHI } & Low users & & & $0.058^{*}$ & $0.549^{*}$ & $0.034^{*}$ & $0.119^{*}$ \\
& & & & $(0.013)$ & $(0.163)$ & $(0.008)$ & $(0.039)$ \\
& \multirow{2}{*}{ High users } & & & -0.013 & -0.413 & $0.026^{*}$ & -0.105 \\
& & & & $(0.016)$ & $(0.475)$ & $(0.011)$ & $(0.108)$ \\
\hline \hline
\end{tabular}

${ }^{*} \mathrm{p}<0.05$; Income is the log equivalent net household income. Marginal effects based on regressions as reported in Table A2. The marginal effects are calculated individually and over each of the components and then averaged over all individuals. The marginal effects of the continuous variables calculated numerically using the following formula: $M E_{i}=\left(p_{i, n e w}-p_{i}\right) /\left(\right.$ Income $\left._{i} / 100\right)$, where $p_{i}$ is the predicted value, $p_{i, n e w}$ is the predicted value assuming a household income of $1 \%$ more than the observed value.

Table 5: Estimated correlation in bivariate probit

\begin{tabular}{l|ccc} 
Equation & $\hat{\rho}$ & $\hat{s e}(\hat{\rho})$ & Observations \\
\hline \hline Deductible & 0.022 & $(0.31)$ & 5152 \\
Add-on & 0.090 & $(0.10)$ & 43458 \\
\hline
\end{tabular}

Standard errors clustered by individuals. Full estimation results in the Appendix, see Table A4

\section{Appendix}


Table A1: Sample means by subgroups

\begin{tabular}{|c|c|c|c|c|}
\hline & $\begin{array}{c}\text { SHI } \\
\text { without add-on }\end{array}$ & $\begin{array}{c}\text { SHI } \\
\text { with add-on }\end{array}$ & $\begin{array}{c}\text { Private } \\
\text { with deductible }\end{array}$ & $\begin{array}{c}\text { Private } \\
\text { without deductible }\end{array}$ \\
\hline Log. equiv. hh-income & 7.30 & 7.55 & 7.90 & 7.82 \\
\hline PCS & 49.15 & 50.86 & 52.63 & 51.29 \\
\hline MCS & 49.75 & 50.15 & 51.59 & 51.22 \\
\hline Self-assessed health & 2.65 & 2.50 & 2.36 & 2.44 \\
\hline BMI high & 0.36 & 0.34 & 0.37 & 0.34 \\
\hline BMI very high & 0.15 & 0.15 & 0.10 & 0.10 \\
\hline Hospital stay prev. year & 0.11 & 0.10 & 0.07 & 0.11 \\
\hline Handicapped & 0.12 & 0.09 & 0.07 & 0.10 \\
\hline Smoker & 0.30 & 0.31 & 0.28 & 0.23 \\
\hline Worries Health & 2.10 & 2.21 & 2.32 & 2.27 \\
\hline Risk attitude health & 2.82 & 3.20 & 3.49 & 3.10 \\
\hline Female & 0.54 & 0.56 & 0.34 & 0.44 \\
\hline Age & 48.0 & 44.90 & 47.29 & 49.13 \\
\hline Foreign & 0.07 & 0.02 & 0.05 & 0.02 \\
\hline Married & 0.62 & 0.63 & 0.64 & 0.64 \\
\hline Children in househ. & 0.30 & 0.34 & 0.33 & 0.27 \\
\hline Full-time employed & 0.36 & 0.49 & 0.62 & 0.34 \\
\hline Self-employed & 0.02 & 0.07 & 0.37 & 0.18 \\
\hline Blue collar worker & 0.18 & 0.15 & 0.01 & 0.01 \\
\hline White collar worker & 0.28 & 0.46 & 0.31 & 0.23 \\
\hline Health job & 0.03 & 0.05 & 0.07 & 0.05 \\
\hline Years of schooling & 11.3 & 12.32 & 13.67 & 13.22 \\
\hline 2002 & 0.34 & 0.25 & 0.31 & 0.34 \\
\hline 2004 & 0.36 & 0.33 & 0.36 & 0.34 \\
\hline Risk attitude finance & 2.24 & 2.76 & 3.45 & 2.89 \\
\hline Attitude cost-sharing & 3.34 & 3.10 & 2.56 & 2.82 \\
\hline Observations & 42675 & 3644 & 3081 & 2470 \\
\hline
\end{tabular}

Source: SOEP, pooled years 2002, 2004, 2006; no civil servants. 
Table A2: Estimation results of latent class hurdle model

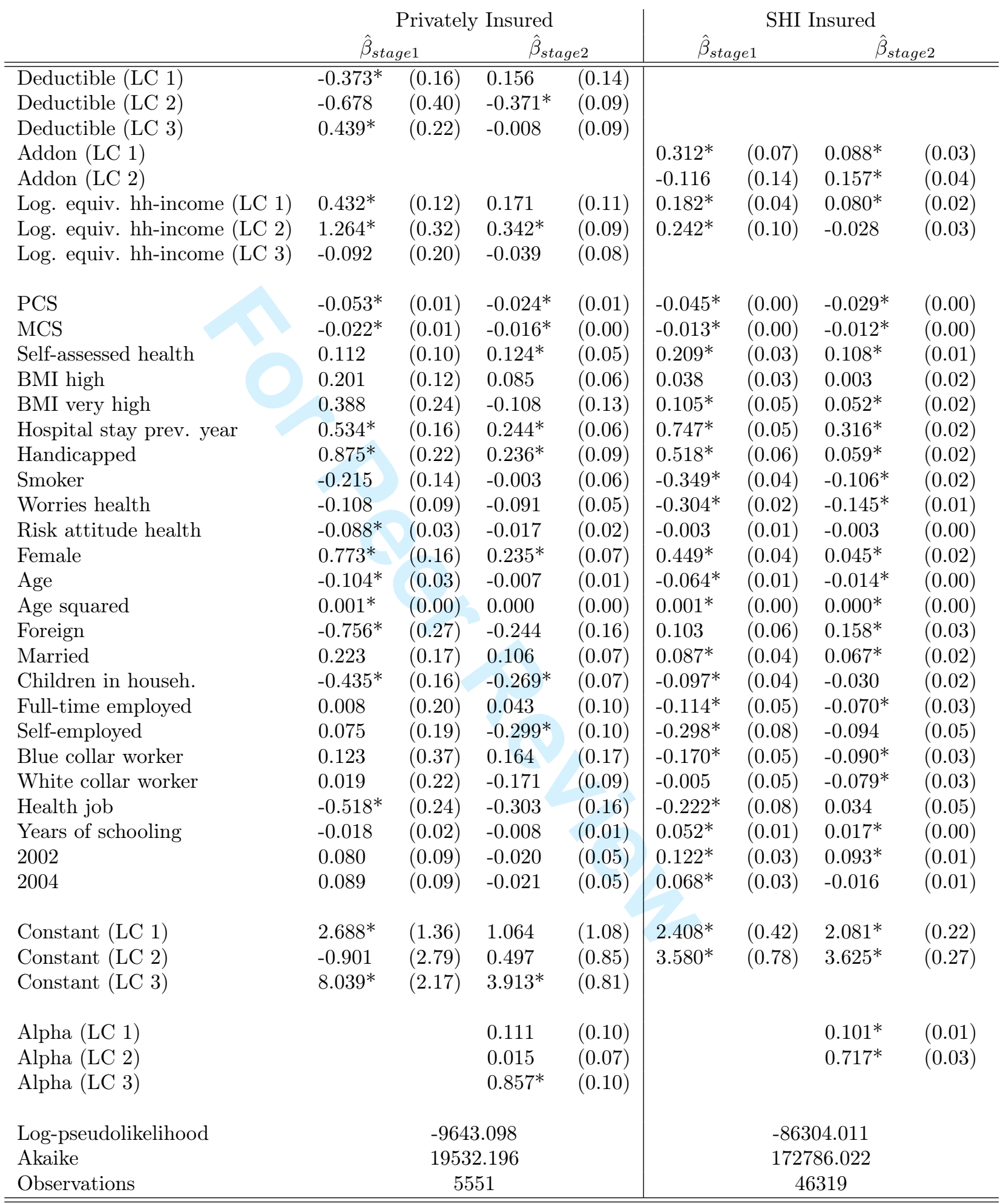

Standard errors in parentheses; ${ }^{*} \mathrm{p}<0.05$; The hypothesis of equality of all parameters across the two stages could be rejected in favour of the hurdle model. "LC" = latent class. Reference groups for dummies: BMI $<=25$ (for BMI high and BMI very high), no full-time employment (for full-time employed), unemployed or out-of-the labour force (for self-employed, blue collar worker, and white collar worker). 
Table A3: Probabilities of latent class membership

\begin{tabular}{l|lllll|ll} 
& \multicolumn{4}{|c|}{ Privately Insured } & \multicolumn{2}{c}{ SHI Insured } \\
& \multicolumn{3}{|c}{$\pi_{1}$} & \multicolumn{2}{c}{$\pi_{2}$} & \multicolumn{2}{c}{$\pi$} \\
& coeff. & std. error & coeff. & std. error & coeff. & std. error \\
\hline \hline Deductible & 0.085 & $(0.32)$ & 0.335 & $(0.36)$ & & \\
Addon & & & & & -0.139 & $(0.15)$ \\
Log. equiv. hh-income & $0.664^{*}$ & $(0.29)$ & 0.582 & $(0.31)$ & -0.149 & $(0.10)$ \\
PCS & -0.023 & $(0.03)$ & -0.037 & $(0.04)$ & -0.003 & $(0.01)$ \\
MCS & 0.013 & $(0.02)$ & 0.009 & $(0.02)$ & -0.004 & $(0.00)$ \\
Self-assessed health & -0.189 & $(0.32)$ & 0.301 & $(0.37)$ & $-0.192^{*}$ & $(0.08)$ \\
BMI high & 0.317 & $(0.31)$ & -0.258 & $(0.31)$ & -0.057 & $(0.09)$ \\
BMI very high & 1.502 & $(1.05)$ & 1.533 & $(0.90)$ & 0.127 & $(0.11)$ \\
Hospital stay prev. year & -0.996 & $(0.65)$ & 0.293 & $(0.56)$ & $-1.131^{*}$ & $(0.13)$ \\
Handicapped & 0.837 & $(0.70)$ & 0.702 & $(0.77)$ & $-0.500^{*}$ & $(0.12)$ \\
Smoker & -0.195 & $(0.36)$ & -0.416 & $(0.32)$ & $-0.181^{*}$ & $(0.09)$ \\
Worries health & $0.770^{*}$ & $(0.31)$ & 0.481 & $(0.32)$ & -0.126 & $(0.08)$ \\
Risk attitude health & $-0.229^{*}$ & $(0.06)$ & $-0.121^{*}$ & $(0.06)$ & 0.006 & $(0.02)$ \\
Female & 0.713 & $(0.38)$ & 0.113 & $(0.34)$ & $-0.250^{*}$ & $(0.10)$ \\
Age & -0.095 & $(0.06)$ & 0.050 & $(0.06)$ & -0.015 & $(0.02)$ \\
Age squared & 0.001 & $(0.00)$ & -0.001 & $(0.00)$ & 0.000 & $(0.00)$ \\
Foreign & -1.193 & $(0.67)$ & -0.186 & $(0.72)$ & 0.276 & $(0.15)$ \\
Married & -0.033 & $(0.44)$ & -0.452 & $(0.37)$ & 0.203 & $(0.10)$ \\
Children in househ. & -0.758 & $(0.45)$ & 0.421 & $(0.38)$ & -0.094 & $(0.10)$ \\
Full-time employed & $1.852^{*}$ & $(0.59)$ & 0.482 & $(0.55)$ & -0.011 & $(0.13)$ \\
Self-employed & 0.355 & $(0.61)$ & 0.617 & $(0.58)$ & -0.083 & $(0.23)$ \\
Blue collar worker & 0.857 & $(1.30)$ & 0.481 & $(1.22)$ & 0.139 & $(0.15)$ \\
White collar worker & $-1.451^{*}$ & $(0.59)$ & -0.731 & $(0.54)$ & -0.210 & $(0.14)$ \\
Health job & 0.861 & $(0.89)$ & 1.317 & $(0.95)$ & 0.250 & $(0.21)$ \\
Years of schooling & $-0.119^{*}$ & $(0.04)$ & -0.048 & $(0.04)$ & $0.037^{*}$ & $(0.02)$ \\
2002 & $1.241^{*}$ & $(0.58)$ & $1.857^{*}$ & $(0.66)$ & $0.489^{*}$ & $(0.19)$ \\
2004 & 0.048 & $(0.55)$ & 0.062 & $(0.64)$ & $0.348^{*}$ & $(0.21)$ \\
Constant & -1.730 & $(3.99)$ & -5.389 & $(4.13)$ & $2.609^{*}$ & $(1.07)$ \\
\hline \hline
\end{tabular}

$* \mathrm{p}<0.05$; Coefficients have to be interpreted relative to the base category in the private insurance regressions. 
Table A4: Bivariate probit results

\begin{tabular}{|c|c|c|c|c|c|c|c|c|}
\hline \multirow{3}{*}{ 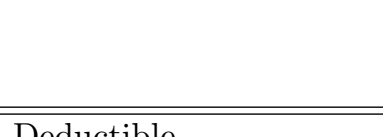 } & \multicolumn{4}{|c|}{ Privately Insured } & \multicolumn{4}{|c|}{ SHI Insured } \\
\hline & \multicolumn{2}{|c|}{ Doctor Binary } & \multicolumn{2}{|c|}{ Deductible } & \multicolumn{2}{|c|}{ Doctor Binary } & \multicolumn{2}{|c|}{ Addon } \\
\hline & $\begin{array}{l}-0.090 \\
\end{array}$ & $(0.51)$ & & & & & & \\
\hline Addon & & & & & -0.046 & $(0.20)$ & & \\
\hline Log. equiv. hh-income & $0.096^{*}$ & $(0.04)$ & 0.019 & $(0.05)$ & $0.131^{*}$ & $(0.02)$ & $0.478^{*}$ & $(0.03)$ \\
\hline PCS & $-0.026^{*}$ & $(0.00)$ & 0.005 & $(0.00)$ & $-0.024^{*}$ & $(0.00)$ & -0.002 & $(0.00)$ \\
\hline MCS & $-0.011^{*}$ & $(0.00)$ & 0.004 & $(0.00)$ & $-0.007^{*}$ & $(0.00)$ & 0.001 & $(0.00)$ \\
\hline Self-assessed healt & $0.109^{*}$ & $(0.04)$ & $0.070^{*}$ & $(0.04)$ & $0.131^{*}$ & $(0.01)$ & -0.012 & $(0.02)$ \\
\hline BMI high & 0.004 & $(0.05)$ & -0.034 & $(0.05)$ & $0.035^{*}$ & $(0.02)$ & 0.014 & $(0.03)$ \\
\hline BMI very high & 0.038 & $(0.08)$ & -0.045 & $(0.08)$ & $0.050^{*}$ & $(0.02)$ & 0.061 & $(0.04)$ \\
\hline Hospital stay prev. year & $0.384^{*}$ & $(0.08)$ & -0.096 & $(0.06)$ & $0.483^{*}$ & $(0.03)$ & $0.084^{*}$ & $(0.03)$ \\
\hline Handicapped & $0.361^{*}$ & $(0.10)$ & -0.033 & $(0.09)$ & $0.350^{*}$ & $(0.03)$ & 0.028 & $(0.04)$ \\
\hline Smoker & -0.094 & $(0.05)$ & -0.009 & $(0.05)$ & $-0.170^{*}$ & $(0.02)$ & $0.079^{*}$ & $(0.03)$ \\
\hline Worries health & $-0.157^{*}$ & $(0.04)$ & 0.007 & $(0.04)$ & $-0.168^{*}$ & $(0.01)$ & 0.018 & $(0.02)$ \\
\hline Risk attitude health & -0.007 & $(0.01)$ & 0.003 & $(0.01)$ & -0.002 & $(0.00)$ & 0.007 & $(0.01)$ \\
\hline Female & $0.245^{*}$ & $(0.05)$ & 0.035 & $(0.06)$ & $0.299^{*}$ & $(0.02)$ & $0.110^{*}$ & $(0.03)$ \\
\hline Age & $-0.031^{*}$ & $(0.01)$ & $0.042^{*}$ & $(0.01)$ & $-0.031^{*}$ & $(0.00)$ & 0.009 & $(0.01)$ \\
\hline Age squared & $0.000^{*}$ & $(0.00)$ & $-0.000^{*}$ & $(0.00)$ & $0.000^{*}$ & $(0.00)$ & $-0.000^{*}$ & $(0.00)$ \\
\hline Foreign & -0.153 & $(0.10)$ & 0.146 & $(0.12)$ & 0.018 & $(0.03)$ & $-0.383^{*}$ & $(0.06)$ \\
\hline Married & 0.084 & $(0.06)$ & $-0.119^{*}$ & $(0.06)$ & 0.017 & $(0.02)$ & -0.009 & $(0.03)$ \\
\hline Children in 1 & -0.012 & $(0.05)$ & 0.055 & $(0.06)$ & -0.038 & $(0.02)$ & $0.102^{*}$ & $(0.03)$ \\
\hline Full-time employed & $-0.291^{*}$ & $(0.11)$ & $0.417^{*}$ & $(0.08)$ & $-0.064^{*}$ & $(0.02)$ & 0.022 & $(0.03)$ \\
\hline Self-employed & 0.006 & $(0.12)$ & $0.455^{*}$ & $(0.09)$ & $-0.161^{*}$ & $(0.04)$ & $0.247^{*}$ & $(0.06)$ \\
\hline Blue collar wor & -0.022 & $(0.16)$ & 0.281 & $(0.16)$ & $-0.117^{*}$ & $(0.03)$ & -0.000 & $(0.04)$ \\
\hline White collar $\mathrm{w}$ & $0.264^{*}$ & (0.c & $0.177^{*}$ & $(0.09)$ & 0.031 & $(0.03)$ & $0.152^{*}$ & $(0.04)$ \\
\hline Health job & $-0.347^{*}$ & $(0.10)$ & $-0.331^{*}$ & $(0.10)$ & $-0.178^{*}$ & $(0.04)$ & 0.010 & $(0.06)$ \\
\hline Years of schooling & $0.014^{*}$ & $(0.01)$ & $-0.014^{*}$ & $(0.01)$ & $0.026^{*}$ & $(0.00)$ & $0.015^{*}$ & $(0.01)$ \\
\hline 2002 & 0.023 & $(0.05)$ & $-0.087^{*}$ & $(0.04)$ & $0.056^{*}$ & $(0.02)$ & $-0.324^{*}$ & $(0.02)$ \\
\hline 2004 & 0.039 & $(0.04)$ & -0.002 & $(0.03)$ & $0.033^{*}$ & $(0.02)$ & $-0.234^{*}$ & $(0.02)$ \\
\hline Risk attit & & & 0.014 & $(0.01)$ & & & $0.018^{*}$ & $(0.01)$ \\
\hline Attitude cost-sharing & & & $-0.117^{*}$ & $(0.02)$ & & & $-0.075^{*}$ & $(0.02)$ \\
\hline Constant & $2.123^{*}$ & $(0.55)$ & $-1.494^{*}$ & $(0.56)$ & $1.237^{*}$ & $(0.22)$ & $-5.020^{*}$ & $(0.32)$ \\
\hline$\rho$ & 0.022 & $(0.31)$ & & & 0.090 & $(0.10)$ & & \\
\hline $\begin{array}{l}\text { Log-pseudolikelihood } \\
\text { Observations }\end{array}$ & & & $\begin{array}{l}5.409 \\
52\end{array}$ & & & & $\begin{array}{l}1.073 \\
58\end{array}$ & \\
\hline
\end{tabular}

${ }^{*} \mathrm{p}<0.05$; Standard errors in parentheses; Estimations done by Stata program biprobit, standard errors clustered by individuals, less observations than in Table A1 because of missing values in the instruments. Reference groups for dummies: BMI $<=25$ (for BMI high and BMI very high), no full-time employment (for full-time employed), unemployed or out-of-the labour force (for self-employed, blue collar worker, and white collar worker). 